\title{
The effect of optically induced blur on the magnitude of the Mueller-Lyer illusion
}

\author{
LAWRENCE M. WARD and STANLEY COREN \\ University of British Columbia, Vancouver, British Columbia, Canada V6T 1W5
}

\begin{abstract}
The magnitude of the Mueller-Lyer illusion was measured under conditions of high and low image blur. Blur was manipulated by altering the focus of an image projected on a screen. Illusion magnitude increased under high blur conditions. This supports the theory that blur-inducing optical imperfections of the eye are partially responsible for illusory effects in figures with converging lines. The data also indicate the importance of testing the acuity of observers in such experiments, since poor refraction can result in artifactual overestimation of illusion magnitude.
\end{abstract}

In 1968 Chiang resuscitated a theory of illusions initially proposed by Einthoven (1898). This theory proposes that a number of sources of purely optical distortion may contribute to illusion magnitude in figures containing intersecting line elements. Chiang (1968) pointed out that the focus of light entering the eye is degraded from the ideal by diffraction of light around the pupillary aperture or by spherical and chromatic aberrations due to the optical action of the cornea and crystalline lens. This results in a retinal image which is somewhat blurred, so that lines are represented on the retina as relatively smooth light distributions rather than step functions. Chiang (1968) assumes that the visual system interprets the peaks of such blur distributions as the locus of contours. If this is the case, the the peak of the blur distribution formed by two intersecting lines will be displaced into the body of the angle formed by the lines, thus displacing the apparent locus of the vertex. If the size, shape, or direction of other linear elements depends on the loci of such vertices, then this displacement could cause a number of systematic distortions such as those associated with the Mueller-Lyer, Zoellner, Wundt-Hering, and Poggendorff illusions.

An experiment conducted by Coren (1969) partially confirmed the predictions of an optical blur theory for the Poggendorff illusion. He reduced the amount of retinal image blur by using artificial pupils and narrowband chromatic filters to reduce the distortions of the image due to pupillary diffraction, as well as spherical and chromatic aberration. The magnitude of the Poggendorff was reduced under such conditions. However, a $70 \%$ reduction in the inferred amount of blur reduced the illusion magnitude by only $15 \%$, indicating that the blur factor is probably not the sole explanation for the Poggendorff distortion.

This research was supported in part by grants from the National Research Council of Canada A9783 and A9958. The authors would also like to thank Donna Bevelander who assisted on the statistical analyses.
The question still remains as to whether increases in blur beyond the usual will increase the magnitude of intersecting line illusions. The latter question is not only theoretically relevant but is also important in light of a recent methodological warning by Coren and Porac (1975). They suggest that uncorrected refractive errors in observers who participate in illusion experiments could lead to artifactually large estimates of the magnitude of the distortion. They contend that blurring of illusion configurations through poorly focused periphpheral optical systems could augment the obtained illusory effect along the same lines suggested by Chiang (1968) and Einthoven (1898).

The following experiment was thus conducted in order to test whether increasing the blur of the retinal image will increase the magnitude of a converging line illusion. In addition, the Mueller-Lyer illusion was used in order to test the generality of the blur theory of illusion formation beyond the Poggendorff configuration.

\section{METHOD}

The stimulus configuration consisted of a Brentano form of the Mueller-Lyer illusion projected on a screen. The illusion consisted of white lines projected on a dark background, as in Figure 1A. The composite shaft length subtended approximately $8 \mathrm{deg}$ of visual angle as measured from the mean viewing distance. Wing length was approximately $1 \mathrm{deg}$ visual angle, and the angle between the wings was $90 \mathrm{deg}$. Image clarity could be controlled by altering the focus on the projector used to present the stimulus. Two levels of image clarity were selected. In the first, the image was displayed upon the screen as sharply as was possible. In the second, the image was defocused so that it was clearly blurred, although the contour elements were still visible, as in Figure 1B. It is somewhat difficult to assess the exact degree of blur obtained in this fashion; however, an apparently equivalent pheonomenal blur can be produced by inserting a 2.5-diopter lens in front of an emmetropic eye.

In order to assess the size of the illusion, a magnitude estimation procedure was employed. Coren and Girgus (1972) have shown that magnitude estimation procedures produce reliable estimates of the magnitude of the Mueller-Lyer illusion. The apparently shorter segment of the shaft (right side of Figures $1 \mathrm{~A}$ and $\mathrm{B}$ ) was designated as being 10 units in length. Using 


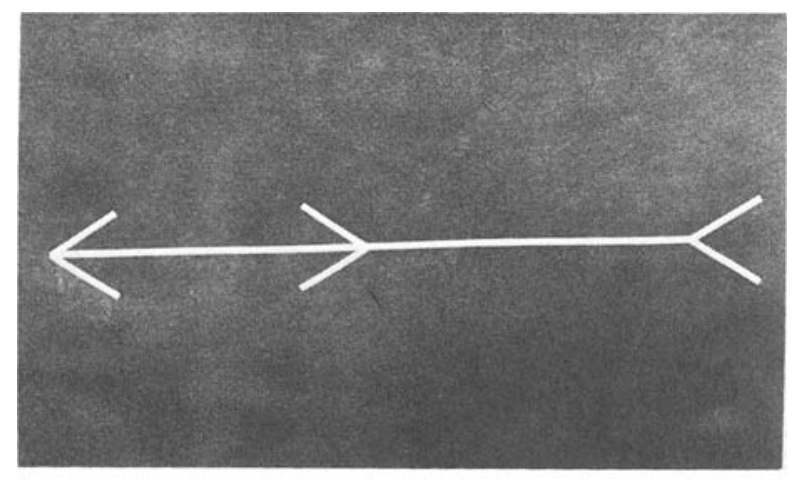

A

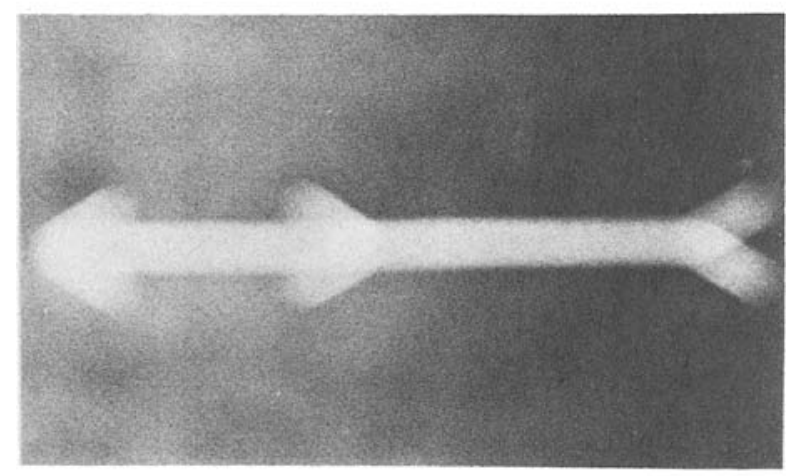

B

Figure 1. (A) The Brentano form of the Mueller-Lyer illusion. (B) A variant of the Mueller-Lyer illusion blurred 2.5 diopters.

this as a modulus, observers were required to estimate the length of the apparently longer shaft in arbitrary units. A total of 103 observers participated in this task. All observers made judgments under both conditions.

\section{RESULTS AND DISCUSSION}

The mean judged length of the apparently longer segment of the Mueller-Lyer figure, measured under standard presentation (in arbitrary units), was 13.13 , which is significantly greater than the modulus length of 10 $(\mathrm{t}=21.14, \mathrm{df}=102, \mathrm{p}<.001)$ that was assigned to the apparently shorter segment. This is an illusion of about $31 \%$ in usual illusion magnitude terms. This value is comparable to magnitudes normally reported in the literature.

When the illusion figure was blurred, the mean estimated length of the longer segment was 17.97 , which is again significantly greater than the apparently shorter segment assigned a $10(\mathrm{t}=27.39, \mathrm{df}=102, \mathrm{p}<.001)$. The mean estimates of the length of the longer segments obtained under the two conditions differ significantly from each other $(\mathrm{t}=13.11, \mathrm{df}=102, \mathrm{p}<.001)$, indicating that illusion magnitude increased significantly for the blurred stimulus. In fact, illusion magnitude was more than doubled by the addition of 2.5 diopters of blur.

The above data are consistent with the speculations of Chiang (1968) and Einthoven (1898), and conceptually replicate Coren's (1969) results using augmentation of external blur of the configuration rather than reduction of blur in the retinal image. It is important to note that this does not suggest that the sole mechanism for the Mueller-Lyer illusion is optical degradation, since, as Coren and Girgus (1973, 1974), Girgus and Coren (1973), and Girgus, Coren, Durant and Porac (1975) have already pointed out, most illusory distortions seem to be a compound of many causal mechanisms. It does, however, highlight the possibility that optical factors may play a role in illusion formation.

These results also sound a methodological note. As Coren and Porac (1975) have pointed out, most investigators in the field of pattern perception and illusions have neglected to report any pretesting of their observers in order to assure that they are visually normal, or at least have vision corrected to normal. To the extent that lack of reports implies lack of such pretesting, many typical observers may be refractively imperfect. For an observer with refractive errors, the perception of a line stimulus is closer to that of our blurred configuration than to that of the normal. As these results indicate, such smearing of the image may result in an overestimation of the illusion strength. If the overestimation is very great (for instance at the 2.5-diopter level employed as the blur manipulation here), the poor refraction can result in overestimations of better than $100 \%$. It thus behooves the experimenter to pretest his sample to insure normal visual acuity.

\section{REFERENCES}

Chiang, C. A new theory to explain geometrical illusions produced by crossing lines. Perception \& Psychophysics, $1968,3,174-176$.

Coren, S. The influence of optical aberrations on the magnitude of the Poggendorff illusion. Perception \& Psychophysics, 1969, 6, 185-186.

Coren, S., \& Grrgus, J. S. Visual spatial illusions: Many explanations. Science, 1973, 179, 503-504.

Coren, S., \& Girgus, J. S. Transfer of illusion decrement as a function of perceived similarity. Journal of Experimental Psychology, 1974, 102, 881-887.

Coren, S., \& Porac, C. The myth of the normal eye: A methodological note. Bulletin of the Psychonomic Society, 1975, 5, 469-470.

Einthoven, W. Eine einfache physiologische Erklarung fur verschiedene geometrisch-opitisch Tauschungen. Pflüger's Archiv fur Physiologie, 1898, 71, 1-43.

Girgus, J. S., \& Coren, S. Peripheral and central components in the formation of visual illusions. American Journal.of Optometry and Archives of the American Optometric Society, 1973, 50, 533-540.

Girgus, J. S., Coren, S., Durant, M., \& Porac, C. The assessment of components involved in illusion formation using a long-term decrement procedure. Perception \& Psychophysics, $1975,18,144-148$.

(Received for publication January 19, 1976.) 